\title{
Education inequality and use of cigarettes, alcohol, and marijuana
}

\author{
Sandro Galea ${ }^{\mathrm{a}, \mathrm{b}, \mathrm{c}, *}$, Jennifer Ahern ${ }^{\mathrm{a}, 1}$, Melissa Tracy ${ }^{\mathrm{a}, 2}$, \\ Sasha Rudenstine ${ }^{\mathrm{a}, 3}$, David Vlahov ${ }^{\mathrm{b}, \mathrm{c}, \mathrm{d}, 4}$ \\ ${ }^{a}$ Department of Epidemiology, University of Michigan School of Public Health, Ann Arbor, MI, USA \\ ${ }^{\mathrm{b}}$ Center for Urban Epidemiologic Studies, New York Academy of Medicine, New York, NY, USA \\ ${ }^{\mathrm{c}}$ Department of Epidemiology, Columbia University Mailman School of Public Health, New York, NY, USA \\ d Department of Epidemiology, Johns Hopkins Bloomberg School of Public Health, Baltimore, MD, USA \\ Received 15 March 2006; received in revised form 5 November 2006; accepted 6 November 2006
}

\begin{abstract}
Education inequality at the neighborhood-level may influence population health and health behavior. We assessed the relations between education inequality and substance use in 59 New York City (NYC) neighborhoods. We used Gini coefficients of education to describe neighborhood education inequality and data from a random-digit-dial phone survey of adult residents of NYC to assess use of substances. Among 1355 respondents (female $=56.2 \%$; white $=35.7 \%$; mean age $=40.4), 23.9 \%(95 \%$ confidence interval $[\mathrm{CI}]=20.3-27.5)$ reported smoking, 39.4\% $(95 \%$ $\mathrm{CI}=35.3-43.4)$ drinking, and $5.4 \%(95 \% \mathrm{CI}=3.6-7.3)$ using marijuana in the previous 30 days. In multilevel models controlling for neighborhood education, neighborhood income inequality, and individual covariates, living in a neighborhood with high education inequality was associated with a greater prevalence of drinking $(p=0.02)$ and of smoking marijuana $(p=0.004)$ but among current drinkers it was associated $(p=0.03)$ with having fewer drinks. The odds of alcohol use $(\mathrm{OR}=1.70)$ and marijuana use $(\mathrm{OR}=3.49)$ were greater in neighborhoods in the 75 th percentile of education Gini compared to neighborhoods in the 25th percentile of education Gini. Statisical interactions suggest that there may be a stronger relation between education inequality and marijuana use in neighborhoods with low mean education than in neighborhoods with higher mean levels of education. These findings, taken together, suggest a complex relation between education inequality and substance use; likelihood of the use of alcohol and marijuana was higher in areas with higher education inequality suggesting potential roles for substance use norms and availability, whereas quantity used among drinkers was higher in areas with low education inequality, suggesting potential roles for both disadvantage and norms. (c) 2006 Elsevier Ireland Ltd. All rights reserved.
\end{abstract}

Keywords: Education; Inequality; Neighborhood; Cigarettes; Alcohol; Marijuana; Drug use

\footnotetext{
* Corresponding author at: Department of Epidemiology, University of Michigan School of Public Health, 1214 South University, Room 243, Ann Arbor, MI 48104-2548, USA. Tel.: +1 734647 9741; fax: +1 7349980006.

E-mail addresses: sgalea@umich.edu (S. Galea), jahern@berkeley.edu (J. Ahern), mstracy@umich.edu (M. Tracy), srudenstine@umich.edu

(S. Rudenstine),dvlahov@nyam.org (D. Vlahov).

${ }^{1}$ Present address: Division of Epidemiology, University of California Berkeley School of Public Health, 140 Warren Hall, Berkeley, CA 94720-7360, USA. Tel.: +1 510643 4922; fax: +1 5106434927 .

2 Present address: Department of Epidemiology, University of Michigan School of Public Health, 1214 South University, Room 233, Ann Arbor, MI 48104-2548, USA. Tel.: +1 734615 9221; fax: +1 7349980006.

${ }^{3}$ Present address: Department of Epidemiology, University of Michigan School of Public Health, 1214 South University, Room 238, Ann Arbor, MI 48104-2548, USA. Tel.: +1 734615 0694; fax: +1 7349980006.

${ }^{4}$ Present address: Center for Urban Epidemiologic Studies, New York Academy of Medicine, 1216 Fifth Avenue, New York City, NY 10029, USA Tel.: +1 212822 7378; fax: +1 2128766220 .
}

\section{Introduction}

Education is often considered one of the "fundamental" determinants of health and a primary indicator of individual socio-economic status (Link and Phelan, 2000; Adler and Ostrove, 1999; Adler and Newman, 2002). The relation between education and health is well-established; persons who are better educated live longer and suffer less morbidity during their lifetimes (Hemingway et al., 2000; Bobak et al., 1999; Lynch et al., 1995). However, the relation between education and use and misuse of substances is less consistent. For example, although it repeatedly has been shown that low educational attainment is associated with greater risk of smoking throughout the life course (SAMHSA, 2003; Barbeau et al., 2004; Helmert et al., 2001; Jefferis et al., 2003, 2004; Gilman et al., 2003), persons with higher education are more likely to drink alcohol (SAMHSA, 2003; Moore et al., 2005; Casswell et al., 2003), although they are less likely to binge drink (SAMHSA, 2003; 
Casswell et al., 2003; Karlamangla et al., 2006). Persons with higher education are also more likely to use marijuana throughout their lifetime (Stenbacka et al., 1993).

In the past two decades a body of work has considered whether group measures of socioeconomic status are associated with health, independent of the role of individual socioeconomic status. In particular, there is a substantial literature assessing the relation between the distribution of income (frequently referred to in the public health literature as "income inequality") and population health (Wilkinson, 1992; Subramanian and Kawachi, 2004; Lynch et al., 2004a,b). Although the evidence in the field remains controversial, recent systematic reviews of the literature suggest that although there is little consistent evidence for a cross-national relation between income distribution and health, there may be a relation between income maldistribution and indicators of poorer health in the United States (US) at the state, city, and neighborhood levels (Lynch et al., 2004a,b).

Although the literature in this regard is sparse, recent work suggests that there also may be a relation between distribution of education and population health (Galea and Ahern, 2005). The presence of people with a wide range of educational attainment within a group may be accompanied by positive externalities ("spill-over" benefits) generated by the presence and actions of persons with high educational attainment (Checchi, 2001; Galea and Ahern, 2005). For example, health education messages developed by health care facilities at the level demanded by their most educated patients would then benefit all of those who use their services. Similarly, more educated persons may have access to persons in power and successfully lobby against cigarette advertising in their neighborhood, as such advertising has been shown to be associated with greater cigarette smoking (Schooler et al., 1996). While such improvements in the determinants of health may be driven by persons who are more educated, they will then be available to all others in a particular area as long as the improved resources are not more costly for individuals to access. Therefore, it is plausible that a small group of persons who are more educated may contribute to the improvement of shared facilities and resources in a given area. These shared facilities and resources, barring significant financial barriers to entry, may contribute to improved well-being among all persons in a particular area. These benefits may be particularly important in the context of health indicators that are likely to be affected by short-term changes in the social environment, such as substance use.

Therefore, distribution of education may be an important determinant of population health. Although in the US everyone has access to primary and secondary school education, there is a wide range in educational attainment (US Census, 2000). There are substantial educational disparities between various racial/ethnic and socioeconomic groups in the US (Christenson and Johnson, 1995; Sandefur and Pahari, 2004; Graetz, 1987) and it has been argued that these disparities may contribute to racial/ethnic inequalities in health (Thomas et al., 2000). However, we are aware of only one previous study that has explicitly studied the role of area-level education distribution as a potential determinant of health. In that paper, the authors showed that education distribution was positively associated with health indicators that that may be sensitive to short term changes in the social environment (homicide, infant mortality, low birthweight, late or no prenatal care) when taking into account neighborhood education, income, and income distribution (Galea and Ahern, 2005).

There is relatively little research on the role of social and contextual (or group-level) variables in determining substance use behaviors (Galea et al., 2004, 2005). Although there is an emerging body of literature that documents an association between living in economically deprived areas and higher prevalence of smoking (Diez-Roux et al., 1997; Kleinschmidt et al., 1995; Jones and Duncan, 1985; Reijneveld, 1998; Ecob and MacIntyre, 2000), and drinking (Hill and Angel, 2005), this evidence is inconsistent. We are not aware of previous work that has explicitly studied the role of area-level education distribution as a potential determinant of substance use, or any other health behavior. In this paper we assessed the relation between education distribution and the use of cigarettes, alcohol, and marijuana in New York City (NYC) neighborhoods. We hypothesized that distribution of education at the neighborhood level would be positively associated with substance use, and that in neighborhoods where there is more heterogenous educational attainment there would be lower use of substances, when accounting for individual income. It was our goal both to assess the potential relation between education distribution and use of substances, and also to further advance empirical inquiry into the role of contextual characteristics in shaping risk of substance use and misuse.

\section{Methods}

\subsection{Individual-level variables}

Individual-level data for this study were obtained from a cross-sectional random digit dial (RDD) household telephone survey that included measures of substance use. The survey, carried out between 25 March and 25 June 2002, was designed to assess mental health in the New York City (NYC) metropolitan area in the aftermath of the 11 September terrorist attacks in NYC. The sampling frame for the survey included all adults in the NYC metropolitan area with over-sampling of residents in NYC; this analysis is limited to residents of NYC.

The cooperation rate, based on the sum of the number of completed interviews, quota outs and screen-outs (i.e. $1570+518+117$ ) divided by the sum of completed interviews, quota outs, screen outs, refusals, and premature terminations (i.e. $1570+518+117+1362+71$ ), was $60 \%$. The final sample of respondents did not differ significantly from the 2000 census estimates of New York City (US Bureau of the Census 2000). The Institutional Review Board of the New York Academy of Medicine reviewed and approved this work. Further details on this survey can be found elsewhere (Galea et al., 2003b; Vlahov et al., 2004).

Respondents were interviewed using a structured questionnaire. The primary outcome variables for this analysis were respondents' cigarette smoking, alcohol drinking, and marijuana smoking. For each of the three substances we asked the following series of questions. First we asked if the respondent had used the substance in the previous 12 months (e.g., "Have you smoked cigarettes in the last 12 months?"). Respondents who answered "Yes" to this question were asked to report on how many days they had used the substance in the 30 days prior to the survey, and the average number of times the substance was used per day. This information was used to calculate the total number of cigarettes smoked, number of alcoholic drinks consumed, and number of times marijuana was smoked in the past 30 days. Of the sample of 1355 NYC residents, 10 respondents $(0.7 \%)$ were missing data for the use of cigarettes in the past 30 days, $21(1.5 \%)$ for 
the consumption of alcohol, and 18 (1.3\%) for marijuana use. For the analyses presented here we examined use of each of these substances individually. The survey also included assessment of demographic characteristics including age, race/ethnicity, gender, yearly household income, and education.

\subsection{Neighborhood definition}

NYC is divided into 59 residential community districts (CDs) by the Department of City Planning. CDs are well-defined units, each with an administrative community board, that as such have political and social a priori significance for their residents (Messner and Tardiff, 1986; Marzuk et al., 1997; Suecoff et al., 1999; Galea et al., 2003a). Examples of these CDs include the Upper West Side in Manhattan and Bedford-Stuyvesant in Brooklyn. These CDs will be referred to as neighborhoods hereafter.

\subsection{Education and education distribution}

We used 2000 US Census data on educational attainment among individuals 25 years or older to estimate mean educational levels and distribution of education in NYC neighborhoods (Bureau of the Census, 2000). Mean educational levels were calculated via the following equation:

$\mu=\sum_{i=1}^{n} p_{i} y_{i}$

where $p_{i}$ is the proportion of individuals at a given level of schooling in the population of interest and $y_{i}$ is the midpoint of (or the most likely value for) the schooling category (e.g., $y_{i}=5.5$ for completion of fifth and sixth grades, $y_{i}=16$ for the completion of a bachelor's degree).

The education Gini coefficient was used to measure the distribution of education and the extent of inequality in each neighborhood (Thomas et al., 2000; Kawachi and Kennedy, 1997; Deaton, 1997). A Gini coefficient of 0 denotes a perfectly equitable education distribution, whereas a coefficient of 1.0 represents maximal maldistribution. The two methods - direct and indirect - used in calculating Gini coefficients have been discussed and explored extensively in the income distribution literature. Briefly, the direct method is "the ratio to the mean of half of the average over all pairs of the absolute deviations between [all possible pairs of people]" (Deaton, 1997 [p. 139]). When the indirect method is used, the Gini coefficient is calculated from the Lorenz curve, which is created by plotting proportions of the population from least to most educated on the $x$-axis and proportions of educational attainment on the $y$-axis. The Gini coefficient is the area between the diagonal line indicating no inequality and the concave line representing the education distribution in a particular population. The Gini coefficient was rescaled to range from 0 to 100 for this analysis so that regression parameter estimates could be more easily interpreted.

Given the sample size in this analysis, we used the small-sample Gini estimation (Thomas et al., 2000). This small sample formula is related, through the factor $N /(N-1)$, to the large-sample Gini calculation. In practical terms, when a sample is large enough, $N /(N-1)$ is approximately equal to 1 , and the smallsample approximation is equivalent to the large-sample formula. This definition is mathematically represented as follows:

$E=\left(\frac{N}{N-1}\right)\left[\left(\frac{1}{\mu}\right) \sum_{i=2}^{n} \sum_{j=1}^{i-1} p_{i}\left|y_{i}-y_{j}\right| p_{j}\right]$

where $E$ is the education Gini coefficient, $N$ the number of individuals in the population of interest, $\mu$ the mean number of years of schooling in the population of interest, $y_{i}$ and $y_{j}$ the years of schooling at different educational attainment levels, and $n$ is the number of levels of educational attainment. We used 16 levels of educational attainment in this study (Barro and Lee, 2001).

\subsection{Income distribution}

In order to adjust for income distribution as a potential confounder of the observed relation, we calculated income Gini coefficients. We used household income data from the 2000 US Census to calculate the Gini coefficient as a measure of income distribution in each NYC neighborhood (Bureau of the Census, 2000).

\subsection{Data analysis}

Statistical weights were used in all analyses to correct potential bias related to the number of household telephones, persons in the household, and oversampling. Weights represented the inverse probability of selection for interview. Hence, the sample weight included a component that was inverse to number of household telephones, proportional to number of persons in the household, and inversely proportional to the population sampling fraction. We described demographic characteristics of the survey population and compared these characteristics to the demographic distribution suggested by the 2000 US Census (Bureau of the Census, 2000). All survey respondents who could not be geocoded (due to missing or incorrect addresses) were excluded from these analyses; we compared characteristics of the persons included in these analyses to those who were excluded to examine the potential for bias due to the exclusion of these participants. We used logistic regression models to test the bivariate relations between the individual and neighborhood-level covariates of interest and prevalence of substance use for each of the three substances. We used linear regression to test bivariate relations between covariates and the frequency of substance use among those who had used a substance. Since the total number of persons who had used marijuana in the 30 days prior to the survey was small (92) we did not have sufficient power to assess the determinants of frequency of marijuana use among marijuana users. The linearity of the relation between each covariate and outcome was assessed using likelihood ratio tests $(p<0.1)$. The prevalence of the use of each substance was calculated and graphed by thirds of education inequality. Generalized estimating equations (GEE) were used to fit separate multilevel multiple logistic regression models that assessed the relation between neighborhood-level covariates (mean educational level, education inequality, and income inequality) and prevalence of use of each of the three substances (Zeger and Liang, 1986; Merlo, 2003); models were also adjusted for individual age, gender, race/ethnicity, income, and educational attainment. To assess the magnitude of the relation between education distribution and likelihood of substance we calculated the odds ratio for percentiles of education distribution (for the range of education Gini coefficients in the dataset) setting the 25 th percentile as the referent. For the models where there was a relation between education Gini and substance use, we constructed separate models to assess statistical interaction between neighborhood education distribution and neighborhood education through the use of interaction terms between education Gini and mean neighborhood education. In order to interpret the interaction terms in the models which included them we calculated the relative odds of substance use for individuals living in neighborhoods with different levels of education Gini and mean education. Finally, among those who had used cigarettes and among those who had used alcohol in the month prior to the survey, separate multilevel linear GEE models were fit to assess the relations between neighborhood mean educational level and education inequality and the number of cigarettes smoked and the number of alcoholic drinks consumed, respectively, in the 30 days prior to the survey assessment. In order to consider whether the associations documented here were particularly influenced by the circumstances of this study, we also reran all the statistical models also adjusting for a variable that described whether the participants were affected by the 11 September 2001 terrorist attacks. This variable indicated whether participants were in the World Trade Center complex during the attacks, were injured during the attacks, lost possessions or property, had a friend or relative killed, lost a job as a result of the attacks, or were involved in the rescue effort.

\section{Results}

Overall, 1570 people responded to the telephone survey. Of these individuals we were able to link 1355 to their neighborhood of residence and all analyses presented have been restricted to this latter sample. There were no significant differences in characteristics of the persons included in these analyses and 
Table 1

Demographic characteristics of survey population

\begin{tabular}{|c|c|c|c|c|c|c|c|c|}
\hline & \multicolumn{2}{|c|}{ Total } & \multicolumn{2}{|c|}{ Included } & \multicolumn{2}{|c|}{ Excluded } & \multirow[t]{2}{*}{ Total vs. $p$-value ${ }^{\mathrm{a}}$} & \multirow[t]{2}{*}{ Included vs. $p$-value ${ }^{\mathrm{b}}$} \\
\hline & $N$ & $\%$ & $N$ & $\%$ & $N$ & $\%$ & & \\
\hline Total & 1570 & & 1355 & & 215 & & & \\
\hline \multicolumn{9}{|l|}{ Age } \\
\hline $18-24$ & 157 & 14.7 & 144 & 16.0 & 13 & 8.7 & 0.999 & 0.297 \\
\hline $25-34$ & 414 & 27.0 & 357 & 27.8 & 57 & 23.3 & & \\
\hline $35-44$ & 329 & 19.6 & 279 & 18.3 & 50 & 25.9 & & \\
\hline $45-54$ & 286 & 18.3 & 248 & 18.0 & 38 & 19.8 & & \\
\hline $55-64$ & 175 & 11.2 & 148 & 11.0 & 27 & 12.3 & & \\
\hline $65+$ & 190 & 9.2 & 134 & 9.0 & 26 & 10.0 & & \\
\hline \multicolumn{9}{|l|}{ Gender } \\
\hline Male & 697 & 44.1 & 616 & 43.8 & 81 & 45.3 & 0.961 & 0.804 \\
\hline Female & 873 & 55.9 & 739 & 56.2 & 134 & 54.7 & & \\
\hline \multicolumn{9}{|l|}{ Race/ethnicity } \\
\hline White & 774 & 35.8 & 682 & 35.7 & 92 & 36.6 & 0.978 & 0.117 \\
\hline Asian & 118 & 6.3 & 102 & 6.3 & 16 & 6.6 & & \\
\hline African-American & 264 & 23.7 & 220 & 24.2 & 44 & 21.1 & & \\
\hline Hispanic & 332 & 28.7 & 291 & 29.7 & 41 & 23.8 & & \\
\hline Other & 53 & 5.5 & 40 & 4.2 & 13 & 12.0 & & \\
\hline \multicolumn{9}{|l|}{ Income } \\
\hline$\$ 100,000+$ & 233 & 10.7 & 213 & 11.3 & 20 & 6.9 & 0.9999 & 0.333 \\
\hline$\$ 75,000-99,999$ & 119 & 10.3 & 102 & 9.8 & 17 & 13.3 & & \\
\hline$\$ 50,000-74,999$ & 221 & 16.5 & 196 & 16.1 & 25 & 18.9 & & \\
\hline$\$ 40,000-49,999$ & 110 & 7.3 & 93 & 6.7 & 17 & 10.8 & & \\
\hline$\$ 30,000-39,999$ & 155 & 14.7 & 134 & 14.9 & 21 & 13.5 & & \\
\hline$\$ 20,000-29,999$ & 161 & 16.9 & 142 & 16.5 & 19 & 19.2 & & \\
\hline$<\$ 20,000$ & 303 & 23.6 & 265 & 24.7 & 38 & 17.4 & & \\
\hline \multicolumn{9}{|l|}{ Education } \\
\hline Graduate degree & 282 & 10.1 & 255 & 10.6 & 30 & 7.9 & 0.9996 & 0.674 \\
\hline College degree & 504 & 27.4 & 442 & 27.9 & 62 & 24.9 & & \\
\hline Some college & 273 & 22.0 & 239 & 21.6 & 34 & 23.9 & & \\
\hline High school graduate/GED & 295 & 24.7 & 248 & 24.0 & 47 & 28.1 & & \\
\hline$<$ High school graduate & 207 & 15.9 & 169 & 16.0 & 38 & 15.2 & & \\
\hline \multicolumn{9}{|c|}{ Directly affected by 11 September } \\
\hline No & 1074 & 70.2 & 909 & 69.6 & 165 & 73.1 & 0.898 & 0.540 \\
\hline Yes & 496 & 29.8 & 446 & 30.4 & 50 & 26.9 & & \\
\hline \multicolumn{9}{|l|}{ Any cigarettes in last 30 days } \\
\hline No & 1194 & 75.2 & 1037 & 76.1 & 157 & 70.4 & 0.825 & 0.299 \\
\hline Yes & 361 & 24.8 & 308 & 23.9 & 53 & 29.6 & & \\
\hline \multicolumn{9}{|c|}{ Any alcoholic drink in last 30 days } \\
\hline No & 794 & 60.7 & 673 & 60.6 & 121 & 61.1 & 0.989 & 0.937 \\
\hline Yes & 747 & 39.3 & 661 & 39.4 & 86 & 38.9 & & \\
\hline \multicolumn{9}{|l|}{ Any marijuana in last 30 days } \\
\hline No & 448 & 94.8 & 1245 & 94.6 & 203 & 96.1 & 0.905 & 0.507 \\
\hline \multirow[t]{2}{*}{ Yes } & & 5.2 & 92 & 5.4 & 10 & 3.9 & & \\
\hline & & an & & & & & Median & Range \\
\hline \multicolumn{9}{|l|}{ Neighborhood characteristics } \\
\hline Mean education & & 60 & & & & & 12.42 & $10.06-16.10$ \\
\hline Education Gini & & 16 & & & & & 0.16 & $0.09-0.26$ \\
\hline
\end{tabular}

a Two-tailed $\chi^{2} p$-value comparing those included in the analysis and the entire sample.

b Two-tailed $\chi^{2} p$-value comparing those included in the analysis and those excluded from the analysis.

the 215 persons excluded from the analyses. Table 1 presents baseline characteristics of the sample used for these analyses. Mean age was 40.4 (standard deviation 12.9), $43.8 \%$ were male, $35.7 \%$ were white, $6.3 \%$ Asian, $24.2 \%$ African-American, and
29.7\% Hispanic. A plurality of participants had an income of under $\$ 20,000$ (24.7\%), $16.5 \%$ had an income between $\$ 20,000$ and $\$ 29,999$, and $16.1 \%$ had an income between $\$ 50,000$ and $\$ 74,999$. Table 1 also compares this group to all the persons 
in the sample and all the persons exlcuded from the analysis (i.e., 215 persons). As shown in Table 1 there were no appreciable differences between the total sample of 1570 persons and the 1355 persons who were included in this analysis, or between those included and those excluded from the analysis. There were no differences between groups either on demographic characteristics or on key measures of substance use considered here, including use of cigarettes, alcohol, or marijuana in the previous 30 days. As shown in Table 1, in the included analytic sample, overall, $23.9 \%$ of persons smoked (95\% confidence interval $[C I]=20.3-27.5), 40.0 \%(95 \% \mathrm{CI}=35.3-43.4)$ used alcohol, and $5.4 \%(95 \% \mathrm{CI}=3.6-7.3)$ used marijuana in the 30 days prior to the survey. These 30-day prevalences of substance use are comparable to national 30-day prevalence estimates of use of these substances (SAMHSA, 2003). Among those who smoked, a mean of 262 cigarettes were smoked in the past 30 days (standard deviation 258.7). Among those who drank alcohol, a mean of 18 alcoholic drinks were consumed in the 30 days prior to the survey (standard deviation 20.9). Table 1 also shows that median neighborhood education across all 59 New York City neighborhoods was 12.4 years (range 10.1-16.1); and mean education Gini coefficient was 0.16 (range $0.09-0.26$ ). This is comparable to values calculated by other authors for the US as a whole (Thomas et al., 2000).

We calculated the prevalence of past 30-day use of each substance by thirds of neighborhood education inequality. Fig. 1 shows the relations between education inequality and prevalence of cigarette smoking, alcohol drinking, and marijuana smoking, unadjusted for mean neighborhood education. We found no association between education inequality and prevalence of cigarette $(p=0.84)$ or marijuana smoking $(p=0.65)$. However, there was a greater prevalence of alcohol use in neighborhoods characterized by low education inequality $(p<0.05)$.

Table 2 presents three multilevel logistic regression models assessing the relations between neighborhood mean education, education Gini coefficient, and individual substance use (cigarettes, alcohol, and marijuana) in the past 30 days. The models are adjusted for individual-level covariates, and the interaction between neighborhood mean education and education inequality is examined. Neither mean education nor education Gini were associated with cigarette smoking in the model adjusted for neighborhood-level characteristics or in the model additionally adjusted for individual-level covariates. The only significant predictors of cigarette use were age $(\beta=-0.02$; $p=0.03)$, being male $(\beta=0.65 ; p=0.02)$, and having completed graduate work $(\beta=-1.06 ; p=0.04)$. Mean education $(\beta=0.62 ; p<0.0001)$ and education Gini $(\beta=0.10 ; p=0.01)$ were both positively associated with alcohol use, adjusting for neighborhood income inequality. These relations persisted after adjustment for individual-level covariates, with higher mean education $(\beta=0.43 ; p=0.0003)$ and higher education inequality ( $\beta=0.09 ; p=0.02)$ associated with greater prevalence of alcohol use in the past 30 days. Other significant predictors of alcohol use included individual-level income $(\beta=0.06 ; p=0.01)$, age $(\beta=-0.03 ; p<0.0001)$, male gender $(\beta=0.64 ; p=0.0002)$, and race/ethnicity $(\beta=-1.72$ for Asians, $p=0.001 ; \beta=-0.66$ for African-Americans, $p=0.02$; and $\beta=-0.90$ for Hispanics, $p=0.003$, all compared to Whites). In a separate fully adjusted model, the interaction term between education Gini and mean education was not significantly associated with any alcohol use $(\beta=-0.01 ; p=0.71)$. Both mean education $(\beta=0.69 ; p=0.01)$ and education Gini ( $\beta=0.22 ; p=0.004)$ were positively associated with marijuana use after controlling for neighborhood income inequality and individual-level covariates; male gen$\operatorname{der}(\beta=-0.10 ; p<0.0001)$ and race/ethnicity $(\beta=-5.95$ for Asians, $p=0.01 ; \beta=-2.08$ for Hispanics, $p=0.005$, both compared to Whites) were also associated with marijuana use. In the model including the interaction term between education Gini and mean education, the interaction term was statistically significant $(\beta=-0.05 ; p=0.03)$. Neighborhood income inequality was not associated with use of any of the three substances in adjusted models.

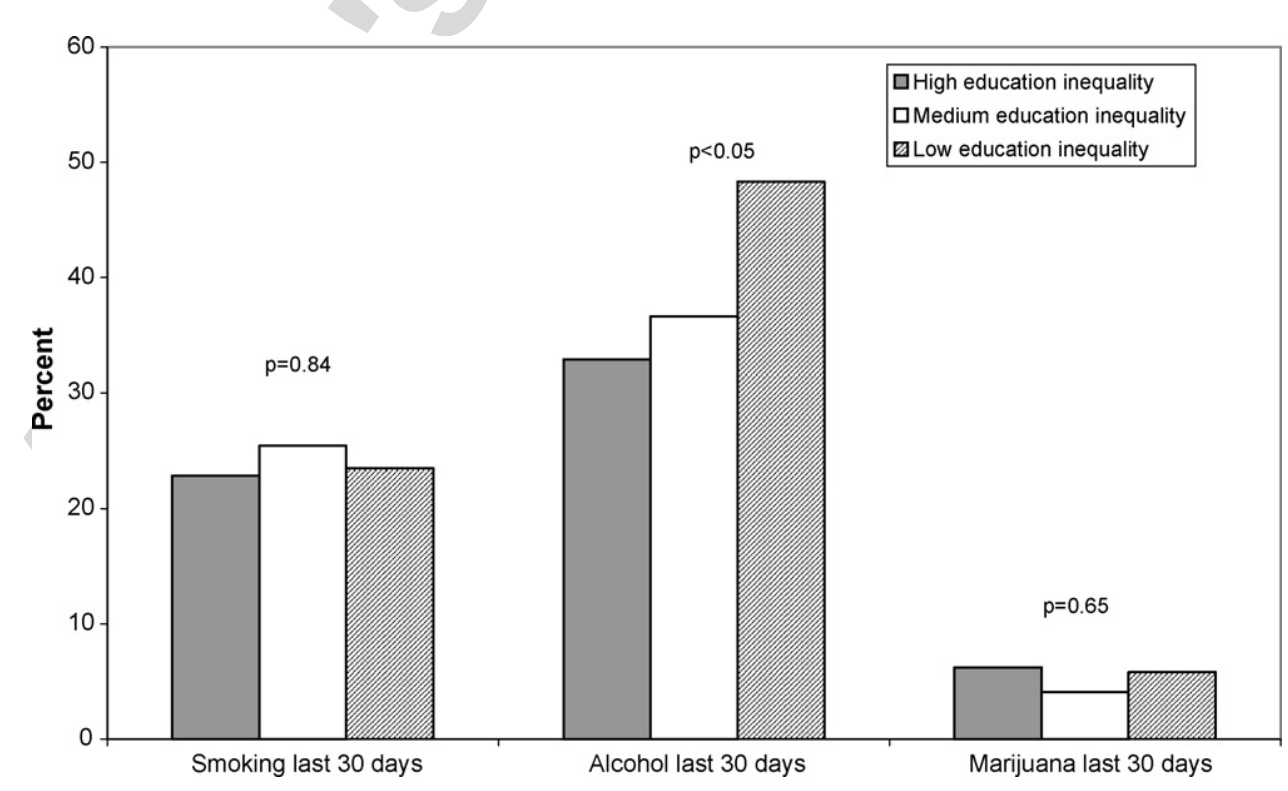

Fig. 1. Prevalence of substance use in the past 30 days by neighborhood education inequality. 
Table 2

Multilevel logistic regression models predicting use of substances

\begin{tabular}{|c|c|c|c|c|c|c|c|c|c|c|c|c|c|c|c|c|}
\hline & \multicolumn{4}{|c|}{ Any cigarettes in last 30 days, $N=1115^{\mathrm{a}}$} & \multicolumn{6}{|c|}{ Any alcoholic drink in last 30 days, $N=1107^{\mathrm{a}}$} & \multicolumn{6}{|c|}{ Any marijuana in last 30 days, $N=1110^{\mathrm{a}}$} \\
\hline & $\beta$ & $p$-Value & $\beta$ & $p$-Value & $\beta$ & $p$-Value & $\beta$ & $p$-Value & $\beta$ & $p$-Value & $\beta$ & $p$-Value & $\beta$ & $p$-Value & $\beta$ & $p$-Value \\
\hline \multicolumn{17}{|l|}{ Neighborhood-level } \\
\hline Intercept & -0.18 & 0.93 & -2.06 & 0.39 & -11.16 & $<0.0001$ & -6.78 & 0.001 & -7.51 & 0.01 & -12.33 & 0.001 & -10.82 & 0.003 & -17.70 & 0.0003 \\
\hline Mean education & -0.09 & 0.49 & 0.1 & 0.55 & 0.62 & $<0.0001$ & 0.43 & 0.0003 & 0.50 & 0.02 & 0.29 & 0.12 & 0.69 & 0.01 & 1.32 & 0.001 \\
\hline Education Gini ${ }^{b}$ & -0.03 & 0.54 & -0.002 & 0.98 & 0.1 & 0.01 & 0.09 & 0.02 & 0.16 & 0.37 & 0.06 & 0.42 & 0.22 & 0.004 & 0.85 & 0.01 \\
\hline Income Gini ${ }^{b}$ & 0.02 & 0.73 & 0.01 & 0.85 & 0.03 & 0.31 & 0.002 & 0.95 & 0.00 & 1.00 & 0.11 & 0.06 & 0.003 & 0.97 & -0.01 & 0.93 \\
\hline \multicolumn{17}{|l|}{ Individual-level } \\
\hline Income & & & -0.06 & 0.08 & & & 0.06 & 0.01 & 0.06 & 0.01 & & & 0.00 & 0.96 & 0.005 & 0.95 \\
\hline Age & & & -0.02 & 0.03 & & & -0.03 & $<0.0001$ & -0.03 & $<0.0001$ & & & -0.10 & $<0.0001$ & -0.10 & $<0.0001$ \\
\hline $\mathrm{Male}^{\mathrm{c}}$ & & & 0.65 & 0.02 & & & 0.64 & 0.0002 & 0.64 & 0.0002 & & & 0.71 & 0.1 & 0.78 & 0.07 \\
\hline \multicolumn{17}{|l|}{ Race/ethnicity ${ }^{\mathrm{d}}$} \\
\hline Asian & & & -0.56 & 0.36 & & & -1.72 & 0.001 & -1.72 & 0.001 & & & -5.95 & 0.01 & -6.23 & 0.004 \\
\hline African-American & & & -0.11 & 0.71 & & & -0.66 & 0.02 & -0.66 & 0.02 & & & -0.22 & 0.65 & -0.27 & 0.58 \\
\hline Hispanic & & & -0.21 & 0.62 & & & -0.9 & 0.003 & -0.91 & 0.004 & & & -2.08 & 0.005 & -2.20 & 0.002 \\
\hline Other & & & -0.83 & 0.29 & & & -0.43 & 0.47 & -0.43 & 0.47 & & & -0.06 & 0.96 & -0.16 & 0.90 \\
\hline \multicolumn{17}{|l|}{ Education $^{\mathrm{e}}$} \\
\hline High school graduate/GED & & & 0.46 & 0.21 & & & 0.04 & 0.94 & 0.05 & 0.93 & & & -0.98 & 0.23 & -0.82 & 0.29 \\
\hline Some college & & & 0.53 & 0.19 & & & 0.37 & 0.46 & 0.37 & 0.46 & & & -0.3 & 0.69 & -0.19 & 0.78 \\
\hline College degree & & & -0.2 & 0.63 & & & 0.69 & 0.22 & 0.69 & 0.22 & & & -1.57 & 0.06 & -1.61 & 0.06 \\
\hline Graduate work & & & -1.06 & 0.04 & & & 0.74 & 0.16 & 0.75 & 0.16 & & & -1.59 & 0.11 & -1.59 & 0.11 \\
\hline Mean education $\times$ education Gini & & & & & & & & & -0.01 & 0.71 & & & & & -0.05 & 0.03 \\
\hline
\end{tabular}

${ }^{a} N$ reflects sample with non-missing data for all variables included in the model.

${ }^{\mathrm{b}}$ Rescaled to range from 0 to 100 .

${ }^{c}$ Female as referent.

${ }^{\mathrm{d}}$ White as referent.

e $<$ High school graduate as referent. 


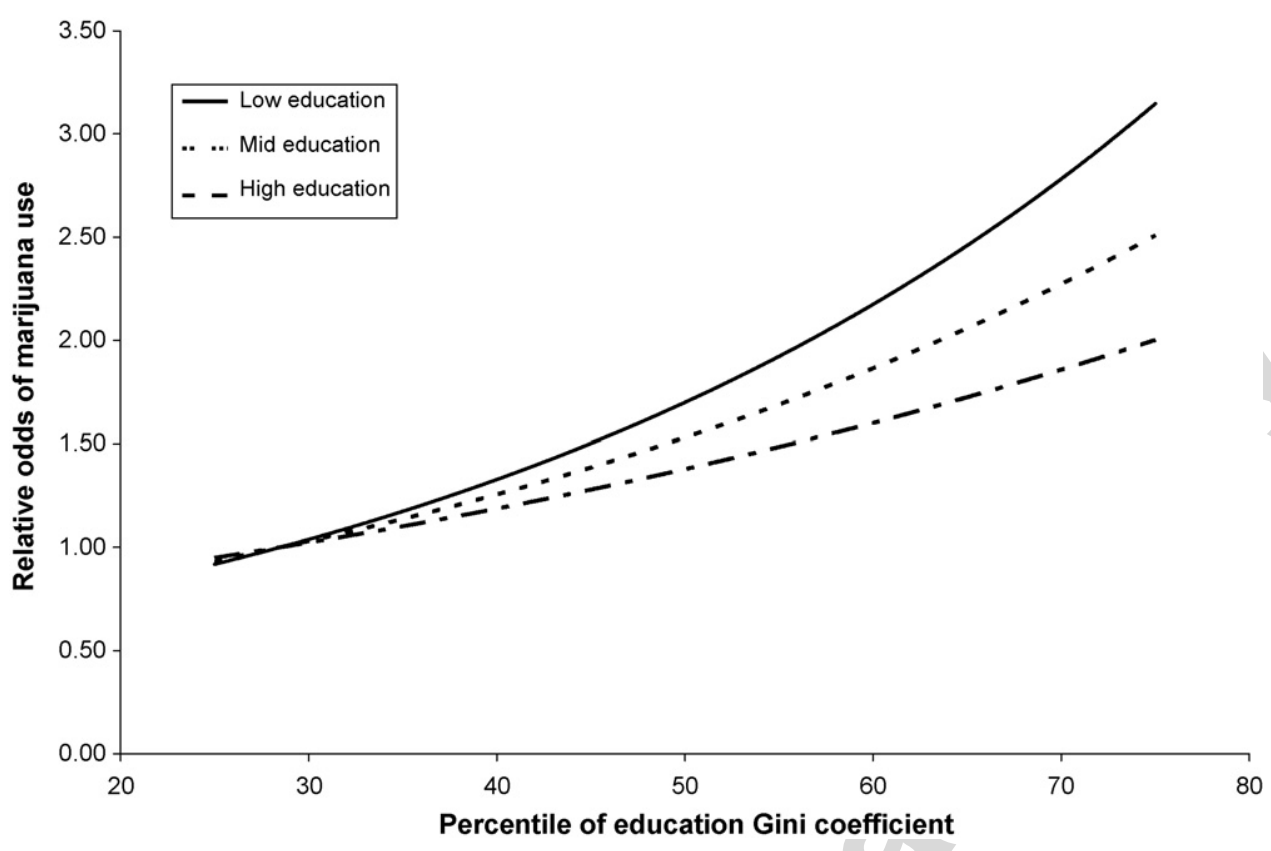

Fig. 2. Relative odds of marijuana use at different values of neighborhood education Gini and neighborhood mean education, predicted from final models including interaction terms. Low education corresponds to the 25 th percentile, mid education to the 50th percentile, and high education to the 75th percentile of neighborhood mean education.

To illustrate the magnitude of the associations found in this analysis, we calculated the relative odds of alcohol use by percentiles of education Gini coefficient. Compared to the 25th percentile, in neighborhoods in the fiftieth percentile of education Gini distribution the relative odds of alcohol use were
$1.24(95 \%$ confidence interval $[\mathrm{CI}]=1.01-1.50)$ and in neighborhoods in the 75 th percentile the relative odds were 1.70 (95\% CI $=1.04-2.79$ ). The relative odds of marijuana use by percentiles of education Gini coefficient were as follows. Compared to the 25 th percentile, in neighborhoods in the fiftieth

Table 3

Multilevel linear regression models predicting use of substances

\begin{tabular}{|c|c|c|c|c|c|c|c|c|}
\hline & \multicolumn{4}{|c|}{$\begin{array}{l}\text { Number of cigarettes in last } 30 \text { days, } \\
\text { among smokers; } N=259^{\mathrm{a}}\end{array}$} & \multicolumn{4}{|c|}{$\begin{array}{l}\text { Number of alcoholic drinks in last } 30 \text { days, } \\
\text { among drinkers; } N=571^{\mathrm{a}}\end{array}$} \\
\hline & $\beta$ & $p$-Value & $\beta$ & $p$-Value & $\beta$ & $p$-Value & $\beta$ & $p$-Value \\
\hline \multicolumn{9}{|l|}{ Neighborhood-level } \\
\hline Intercept & 169.13 & 0.78 & 629.92 & 0.29 & -9.12 & 0.82 & 2.86 & 0.95 \\
\hline Mean education & 19.29 & 0.64 & -31.01 & 0.32 & -1.37 & 0.57 & -2.44 & 0.39 \\
\hline Education Gini $^{\mathrm{b}}$ & 3.62 & 0.85 & -5.81 & 0.64 & -0.02 & 0.09 & -0.02 & 0.04 \\
\hline Income Gini $^{\mathrm{b}}$ & -4.73 & 0.71 & -2.32 & 0.82 & 0.02 & 0.01 & 0.02 & 0.004 \\
\hline \multicolumn{9}{|l|}{ Individual-level } \\
\hline Income & & & 3.91 & 0.58 & & & -0.87 & 0.01 \\
\hline Age & & & 4.64 & 0.01 & & & 0.03 & 0.84 \\
\hline Male $^{c}$ & & & 119.67 & 0.01 & & & 6.79 & 0.04 \\
\hline \multicolumn{9}{|l|}{ Race/ethnicity ${ }^{\mathrm{d}}$} \\
\hline Asian & & & -99.79 & 0.23 & & & 1.45 & 0.84 \\
\hline African-American & & & -159.69 & 0.01 & & & -7.50 & 0.24 \\
\hline Hispanic & & & -117.22 & 0.11 & & & -2.62 & 0.62 \\
\hline Other & & & -255.87 & 0.02 & & & -14.47 & 0.02 \\
\hline \multicolumn{9}{|l|}{ Education $^{\mathrm{e}}$} \\
\hline High school graduate/GED & & & 54.56 & 0.49 & & & 5.41 & 0.45 \\
\hline Some college & & & 9.52 & 0.92 & & & 2.69 & 0.60 \\
\hline College degree & & & 143.02 & 0.24 & & & 6.19 & 0.28 \\
\hline Graduate work & & & 45.21 & 0.79 & & & -1.29 & 0.80 \\
\hline
\end{tabular}

${ }^{\text {a }} N$ reflects sample with non-missing data for all variables included in the model.

b Rescaled to range from 0 to 100 .

c Female as referent.

d White as referent.

e $<$ High school graduate as referent. 
percentile of education Gini distribution the relative odds of marijuana use were $1.65(95 \% \mathrm{CI}=1.12-2.41)$ and in neighborhoods in the 75 th percentile the relative odds were 3.49 (95\% $\mathrm{CI}=1.33-9.15)$.

Fig. 2 shows the relative odds of marijuana use for different levels of education Gini among neighborhoods with low different levels of mean education (ranging from the 25th to the 75th percentile in the data), as predicted from the final models including the statistically significant interaction terms for these two variables. Among neighborhoods with low mean education, relative odds of marijuana use for individuals living in neighborhoods in the 75 th percentile of education distribution were 3.39 (compared to the 25 th percentile of education Gini). For mid education neighborhoods, relative odds of marijuana use were 2.66 and for high education neighborhoods, relative odds were 2.09, also comparing neighborhoods in the 75 th percentile of education Gini to the 25 th percentile.

In multilevel linear regression models assessing the relations between education inequality and frequency of cigarette use and alcohol use in the past 30 days among those who used each substance (Table 3 ), neither neighborhood mean education $(p=0.32)$ nor education inequality $(p=0.63)$ were significantly associated with the quantity of cigarettes smoked. However, controlling for neighborhood education level, income distribution, and individual-level characteristics, living in a neighborhood with high education inequality was associated with fewer drinks consumed in the past month $(\beta=-2.41 ; p=0.03)$ among those who reported any alcohol use in the past month. In contrast, living in a neighborhood with high income inequality was associated with more drinks consumed in the past month $(\beta=1.55$; $p=0.004)$. Further adjustment to account for exposure to the 11 September 2001 terrorist attacks did not appreciably change any of the parameter estimates in the models of interest in this analysis (data not shown).

\section{Discussion}

Neighborhood-level distribution of education attainment was significantly associated with alcohol consumption and marijuana use but not cigarette use in this analysis. In multilevel models adjusting for individual and neighborhood education and other covariates, higher education inequality was associated with higher prevalence of drinking. The odds of alcohol use were 1.70 times higher in neighborhoods in the 75 th percentile of education distribution compared to neighborhoods in the 25th percentile; comparable relative odds for marijuana use were 3.49. However, among those who drink, living in neighborhoods of higher education inequality was associated with fewer drinks consumed. There was a significant interaction between neighborhood education distribution and neighborhood mean education for marijuana use such that education distribution was more strongly associated with marijuana use in neighborhoods with low mean education, with higher use in neighborhoods with more unequally distributed education levels.

There are several reasons why contextual variables in general, and distribution of education at the neighborhood level in particular, may be associated with substance use. First, neigh- borhood characteristics may increase levels of psychological distress (Aneshensel and Sucoff, 1996) and drug use may occur for the relief of states of stress (Rhodes and Jason, 1990; Lindenberg et al., 1994). There is ample research demonstrating that stressful life events occur with greater frequency in neighborhoods with low levels of income and education (Fang et al., 1998) and that substance use may be a way to cope with these events (Boardman et al., 2001). Second, adverse neighborhood conditions may undermine individuals' psychological coping resources and make use of substances more likely (Wilson, 1996). Third, it is possible that neighborhood disadvantage decreases social resources available to individuals, resulting in more limited assistance in coping with daily stresses, and fewer resources to overcome substance use once initiated. Fourth, drug-related behaviors may be related to neighborhood social norms through mechanisms unique to different neighborhoods and population groups (Linsky et al., 1986; Kaplan et al., 2001). Fifth, differential neighborhood availability of substances may be directly associated with different levels of drug use independent of individual-level factors. For example, it has been shown that alcohol outlet density is related to higher levels of alcohol consumption (Scribner et al., 2000). Targeted advertising in particular neighborhoods may increase awareness and desirability of substances (Donovan et al., 2002).

The first three postulated mechanisms to explain relations between neighborhood characteristics and substance use suggest that more disadvantaged neighborhoods (e.g., those with lower educational attainment and lower levels of education inequality) would be expected to have higher prevalence and frequency of substance use due to stress, stressful life events, or diminished coping or other resources. The last two postulated mechanisms leave open the question of how neighborhood disadvantage might relate to substance use, as substance use norms and availability of substances may not correlate with disadvantage. For example, in NYC socioeconomically disadvantaged neighborhoods have more liquor stores, but advantaged neighborhoods have more bars and restaurants that serve liquor. Overall, socioeconomically advantaged neighborhoods have more sources of liquor than disadvantaged neighborhoods (New York State Division of Alcoholic Beverage Control/State Liquor Authority, 2002). The complex relations observed in this study between education distribution in neighborhoods and current use of different substances suggest that disadvantage-related mechanisms as well as substance use norm and substance availability mechanisms may be operating on different aspects of substance use. We showed that education distribution is associated with alcohol use in multilevel models such that neighborhoods with higher mean education and higher education inequality had a higher prevalence of alcohol use and of marijuana use, suggesting a role of substance use norms or substance availability mechanisms. However, we also showed that lower education inequality is associated with a higher number of drinks consumed among those who drink, suggesting roles for both the disadvantage and substance use norms-related mechanisms. Therefore, in neighborhoods with narrow distributions of education, those who drink may consume more heavily due to stress levels or lack of coping resources. Conversely, in neighborhoods where at least 
some people have higher education, awareness about the consequences of heavy alcohol drinking may moderate the amount of alcohol consumed by those who drink.

In general, the broader range of educational attainment within neighborhoods of high education inequality may result in the availability of salutary materials and human resources otherwise absent in neighborhoods with low education inequality. For example, the presence of a few individuals with higher education may benefit all residents of the neighborhood by bringing a variety of advantageous resources ranging from social and health services to fresh food markets. Furthermore, as persons with high educational attainment are likely to have had access to public goods during their education, they may actively contribute to social welfare and cohesion, which would improve the general population health. Our results extend previous work in suggesting that the influence of education distribution and income distribution differ with respect to health and health behaviors (Kawachi and Kennedy, 1999; Kaplan et al., 1996; Galea and Ahern, 2005). Specifically, while maldistribution of income was associated with a higher number of drinks consumed among those who drink, maldistribution of education was associated with a lower number of drinks consumed among those who drink.

We did not find any associations between education distribution and smoking. This furthers the debate in the literature between work that has shown that contextual factors are associated with cigarette use (Diez-Roux et al., 1997; Kleinschmidt et al., 1995; Jones and Duncan, 1985; Reijneveld, 1998; Ecob and MacIntyre, 2000) and work that has not (Tseng et al., 2001). These differences may be explained both by the methodologic differences (including contextual units of analysis) between these studies and by the potential presence of multiple mechanisms, each relevant in different contexts, that determine substance use.

The literature on contextual determinants of illicit drug use is sparse (Galea et al., 2003c). We are aware of only one other empirical study that has assessed contextual determinants of alcohol, cigarette, and marijuana use in the same population sample (Galea et al., in press). This work also suggests similarities between the determinants of alcohol and marijuana use in contrast to cigarette use. It is plausible that since cigarettes have a greater potential for dependence than either alcohol or marijuana (Kandel et al., 1997), current cigarette use is determined by earlier characteristics of the life-course, while contemporaneous contextual variables may have an effect on alcohol and marijuana use. This observation, if replicated, has substantial implications for prevention efforts and merits further research. We note that we also found statistical interaction suggesting that education inequality is more strongly associated with marijuana use in neighborhoods with low mean education, with higher use in neighborhoods with more unequally distributed education levels. In contrast, there was no statistically significant interaction in the models predicting alcohol use. This further hints at the complexity of the role that neighborhood-level social domains may play in influencing risk of substance use. It is plausible that the mechanistic relations undelrying the education Gini and marijuana use relation are different than those underlying the relation between education Gini and alcohol use and that the key mechanisms that explain the results documented here operate differently in the determination of marijuana use at different absolute average level of neighborhood education.

There are several limitations to this study. We used data from a study of residents of New York City in the aftermath of the 11 September attacks. It is possible that the relations observed here are particular to a period of heightened concern due to a national disaster and are not generalizable to other contexts. However, this data was collected more than 6 months after the attacks and there is no evidence that the increase in substances used in New York City after this disaster was differential across geographic areas suggesting that this concern is unlikely to affect the observations documented here. To further control for the possibility that the results documented here were influenced by study circumstance, we adjusted for exposure to the 11 September 2001 terrorist attacks in all models considered here. The absence of any appreciable change in parameters of interest in these models is reassuring that the findings documented here are not attributable to the circumstances of this particularly study. By studying intraurban differences in the largest city in the United States, the generalizability to other smaller cities or non-urban environments is potentially limited. Future analyses would have to consider the role of education inequality, if any, in different contexts and at different geographic levels. The survey data used here were collected through telephone interviews, raising the possibility of under-reporting of substances used. This is again unlikely given the comparability of substance use documented here to national estimates and the growing evidence to suggest that estimates obtained through telephone assessments are valid when compared to in-person assessments (Midanik and Greenfield, 2003; Nelson et al., 2003). Although we controlled for the available relevant individual and neighborhood-level variables it is possible that residual cross-level confounding or confounding by covariates not considered here could explain the observed relations among neighborhood characteristics and substance use measures. Consistent with previous research (Marzuk et al., 1997), we used community districts as proxies for neighborhoods in NYC. Definitions of relevant neighborhood units is challenging and these units, while large, are probably more meaningful analytic units than census tracts or zip codes, common units of analysis in the study of neighborhood-level effects. However, it is important to note that all findings that assess contextual determinants need to be considered carefully with respect to the contextual levels selected and ultimately depend on the theoretic rationale as to why a particular neighborhood unit may matter (Galea and Ahern, 2006). We suggest that the hypothesized mechanisms that may explain an association between education distribution and substance use involve the sharing of human and social resources that would primarily manifest at the small-area level. The observation that education inequality is associated with substance use at the neighborhood level does not preclude the possibility that education inequality may be an important determinant at county, state, or national levels.

In this regard, we note that one of the central challenges in work like the one carried out here is operationalzing neighborhoods. Although operationalizing or defining the rel- 
evant group-level unit of analysis is straightforward in some cases such as institutional settings (e.g. schools) or political boundaries (e.g., states), it can be more challenging in other cases-especially with regard to neighborhoods. The bounding or definition of neighborhoods in neighborhood health research has garnered a lot of recent academic attention (O'Campo, 2003; Galea and Ahern, 2006). As with any exposure, bias can result if the neighborhood construct of interest (in this case education inequality) does not map onto the units chosen for operationalizing neighborhoods and their constructs. Defining neighborhoods (or any relevant unit) mainly threatens construct validity, although it threatens internal validity as well (e.g. non-differential exposure misclassification tends to bias the effect estimate towards the null). Therefore incorrectly bounding neighborhoods, or any spatial unit, may result in empirical problems.

The issue of how to define neighborhoods may also be a conceptual one. For example, how an outsider defines neighborhood boundaries may be different from how a resident him/herself does. Is also is likely that there is heterogeneity within a certain neighborhood as to how residents define their neighborhood and that the underlying construct of neighborhood varies for different people. If we are interested in social exposures that affect health, as we are in this paper, then resident perceptions or definitions of neighborhood may be more relevant for that examination than in the sudy of other factors such as, for example, formal policies which are operationalized according to administrative boundaries (Diez Roux, 2001). Also, some processes occurring in neighborhoods that we may hypothesize to affect health are not necessarily contained within any given spatial boundary (O'Campo, 2003). Although the challenges for operationalizing relevant neighborhoods are important to consider as we weigh choosing a level of analysis, this operationalization should not paralyze empiric investigation (Diez Roux, 2001). Since different phenomena may operate at different scales to affect health, multiple appropriate neighborhood units may be defined to accommodate inclusion of the multiple processes that comprehensively describe how a particular social process shapes health and behavior (O'Campo, 2003). Ultimately a multitude of different groups/units may be relevant for a specific research question (Diez Roux, 2004).

We also note that much as there is concern about generalizability of work such as this across different neighborhood units, there are further considerations about generalizing neighborhood research to different local and national contexts. There is burgeoning evidence that observations about group-level determination of health vary across countries (Lynch et al., 2004a) and future work that aims to replicate the observations we document in this paper may fruitfully consider both different ways of operationalizing neighborhoods and replication (or refutation) of these observations in different countries.

We used Census data from 2000 and it is difficult to know how well this information represents conditions of neighborhoods in NYC in 2002 and if any changes may account for some of the observed associations. Also, inferences about the patterns of marijuana use prevalence are limited by the relatively low prevalence of marijuana use. We also note that although we assess our observations with tests of statistical significance, these tests are predicated on significance levels set for each test alone. Type I error rates (false positives) apply to each test, not to them all taken together, and there remains the possibility that our observations are due to chance alone. Further replication of these observations in other studies would be needed to provide us with confidence that these observations are not accounted for by chance alone. Finally our data pertain strictly to substance use and inferences should not be extended from these observations to either substance abuse or dependence.

This study does not, in and of itself, offer much guidance about policies that can be implemented to reduce substance use and misuse in urban environments. As we note earlier in this paper, this is only the second paper of which we are aware that has explicitly considered how distribution of education at the neighborhood level may be associated with use of substances. The findings here both illustrate the potential contribution of contextual determinants to the use of substances and suggest the complexity of the relations between contextual factors and substance use behavior. Further inquiry is needed to investigate the mechanisms underlying the associations between education inequality and substance use. We suggest that such inquiry is worth pursuing. It has long been established in thinking about population health that change at the level of fundamental "upstream" determinants of health has the potential to influence population health more profoundly than intervention targeted at individual determinants of behavior, health, or disease. Considering neighborhood determinants of individual substance use risk may present important opportunities for intervention once further work has been conducted to clarify and explore the relations that are documented in this analysis.

\section{Acknowledgements}

Funded in part by National Institutes of Health grants DA 017642 and MH 066391. The authors would like to thank the anonymous reviewers and the editor for comments that substantially helped improve the manuscript.

\section{References}

Adler, N.E., Newman, K., 2002. Socioeconomic disparities in health: pathways and policies. Inequality in eduation, income, and occupation exacerbates the gapes between the health of "haves" and "have-nots". Health Aff. (Millwood) $21,60-76$

Adler, N.E., Ostrove, J.M., 1999. Socioeconomic status and health: what we know and what we don't. Ann. N.Y. Acad. Sci. 896, 3-15.

Aneshensel, C.S., Sucoff, C.A., 1996. The neighborhood context of adolescent mental health. J. Health Soc. Behav. 37, 293-310.

Barbeau, E.M., Krieger, N., Soobader, M., 2004. Working class matters: socioeconomic disadvantage, race/ethnicity, gender, and smoking in NHIS 2000. Am. J. Public Health 94, 269-278.

Barro, R.J., Lee, J.W., 2001. International Data on Educational Attainment: Updates and Implications. Center for International Development, Harvard University, Cambridge, MA, Accessed on March 13, 2006, http://econ.korea.ac.kr/prof/jwlee/files/lee\%20oep(final)1.dat.pdf.

Boardman, J.D., Finch, B.K., Ellison, C.G., Williams, D.R., Jackson, J.S., 2001. Neighborhood disadvantage, stress, and drug use among adults. J. Health Soc. Behav. 42, 151-165. 
Bobak, M., Hertzman, C., Skodova, Z., Marmot, M., 1999. Socioeconomic status and cardiovascular risk factors in the Czech Republic. Int. J. Epidemiol. 28, 46-52.

Bureau of the Census, 2000. STF-3A Files. Accessed on 20 July 2004, http:// www.census.gov/main/www/cen2000.html.

Casswell, S., Pledger, M., Hooper, R., 2003. Socioeconomic status and drinking patterns in young adults. Addiction 98, 601-610.

Checchi, D., 2001. Education, Inequality, and Income Inequality. Distributional Analysis Research Programme, London, Accessed on 13 March 2006 http://sticerd.1se.ac.uk/dps/darp/darp52.pdf.

Christenson, B.A., Johnson, N.A., 1995. Educational inequality in adult mortality: an assessment with death certificate data from Michigan. Demography $32,215-229$.

Deaton, A., 1997. The Analysis of Household Surveys: a Microeconomic Approach to Development Policy. Johns Hopkins University Press, Baltimore.

Diez Roux, A.V., 2001. Investigating neighborhood and area effects on health [comment]. Am. J. Public Health 91 (11), 1783-1789.

Diez-Roux, A.V., Nieto, F., Muntaner, C., Tyroler, H.A., Comstock, G.W., Shahar, E., Cooper, L.S., Watson, R.L., Szklo, M., 1997. Neighborhood environments and coronary heart disease: a multilevel analysis. Am. J. Epidemiol. 146, 48-63.

Diez Roux, A.V., 2004. The study of group-level factors in epidemiology: rethinking variables, study designs, and analytical approaches. Epidemiol Rev. 26 (1), 104-111.

Donovan, R.J., Jancey, J., Jones, S., 2002. Tobacco point of sale advertising increases positive brand user imagery. Tob. Control 11, 191-194.

Ecob, R., MacIntyre, S., 2000. Small area variations in health related behaviors; do these depend on the behavior itself, its measurement, or on personal characteristics? Health Place 6, 261-274.

Fang, J., Madhavan, S., Bosworth, W., Alderman, M.H., 1998. Residential segregation and mortality in New York City. Soc. Sci. Med. 47, 469-476.

Galea, S., Ahern, J., 2005. Distribution of education and population health: an ecological analysis of New York City neighborhoods. Am. J. Public Health 95, 2198-2205

Galea, S., Ahern, J., Vlahov, D., Coffin, P.O., Fuller, C., Leon, A.C., Tardiff, K. 2003a. Income distribution and risk of fatal drug overdose in New York City neighborhoods. Drug Alcohol Depend. 70, 139-148.

Galea, S., Vlahov, D., Resnick, H., Ahern, J., Susser, E., Gold, J., Bucuvalas, M., Kilpatrick, D., 2003b. Trends in probable posttraumatic stress disorder in New York City after the September 11 terrorist attacks. Am. J. Epidemiol. $158,514-524$.

Galea, S., Ahern, J., Vlahov, D., 2003c. Contextual determinants of drug use risk behavior: a theoretic framework. J. Urban Health 80, i50-i58.

Galea, S., Nandi, A., Vlahov, D., 2004. The social epidemiology of substance use. Epidemiol. Rev. 26, 36-52.

Galea, S., Rudenstine, S., Vlahov, D., 2005. Drug use, misuse, and the urban environment. Drug Alcohol Rev. 24, 127-136.

Galea, S., Ahern, J., Tracy, M., Vlahov, D., in press. Neighborhood income and income distribution and the use of cigarettes, alcohol, and marijuana. Am J. Prev. Med.

Galea, S., Ahern, J., 2006. Considerations about specificity of association, causal pathways, and heterogeneity of association in multilevel thinking. Am. J. Epidemiol. 163 (12), 1079-1082.

Gilman, S.E., Abrams, D.B., Buka, S.L., 2003. Socioeconomic status over the life course and stages of cigarette use: Initiation, regular use, and cessation. J. Epidemiol. Community Health 57, 802-808.

Graetz, B., 1987. Cohort changes in educational inequality. Soc. Sci. Res. 16, 329-344.

Helmert, U., Borgers, D., Bammann, K., 2001. Social determinants of smoking behavior in Germany: results of a 1995 micro-census. Soz. Praventivmed. $46,172-181$

Hemingway, H., Shipley, M., Macfarlane, P., Marmot, M., 2000. Impact of socioeconomic status on coronary mortality in people with symptoms, electrocardiographic abnormalities, both or neither: the original Whitehall study 25-year follow up. J. Epidemiol. Community Health 54, 510-516.

Hill, T.D., Angel, R.J., 2005. Neighborhood disorder, psychological distress, and heavy drinking. Soc. Sci. Med. 61, 965-975.
Jefferis, B., Graham, H., Manor, O., Power, C., 2003. Cigarette consumption and socio-economic circumstances in adolescence as predictors of adult smoking. Addiction 98, 1765-1772.

Jefferis, B., Power, C., Graham, H., Manor, O., 2004. Effects of childhood socioeconomic circumstances on persistent smoking. Am. J. Public Health 94, 279-285.

Jones, K., Duncan, C., 1985. Individuals and their ecologies: analyzing the geography of chronic illness within a multilevel modeling framework. Health Place 1, 27-40.

Kandel, D., Chen, K., Warner, L.A., Kessler, R.C., Grant, B., 1997. Prevalence and demographic correlates of symptoms of last year dependence on alcohol, nicotine, marijuana and cocaine in the U.S. population. Drug Alcohol Depend. 44, 11-29.

Kaplan, C.P., Napoles-Springer, A., Stewart, S.L., Perez-Stable, E.J., 2001. Smoking acquisition among adolescents and young Latinas: the role of socio-environmental and personal factors. Addict. Behav. 26, 531-550.

Kaplan, G.A., Pamuk, E.R., Lynch, J.W., Cohen, R.D., Balfour, J.L., 1996. Inequality in income and mortality in the United States: analysis of mortality and potential pathways. Br. Med. J. 312, 999-1003.

Karlamangla, A., Zhou, K., Reuben, D., Greendale, G., Moore, A.A., 2006. Longitudinal trajectories of heavy drinking in adults in the United States of America. Addition 101, 91-99.

Kawachi, I., Kennedy, B.P., 1997. The relationship of income inequality to mortality: does the choice of indicator matter? Soc. Sci. Med. 45, 1121-1127.

Kawachi, I., Kennedy, B.P., 1999. Income inequality and health: pathways and mechanisms. Health Serv. Res. 34, 215-227.

Kleinschmidt, I., Hills, M., Elliott, P., 1995. Smoking behavior can be predicted by neighborhood deprivation measures. J. Epidemiol. Community Health 49 (Suppl. 2), S72-S77.

Lindenberg, C.S., Reiskin, H.K., Gendrop, S.C., 1994. The social stress model of substance abuse among childbearing-age women: a review of the literature. J. Drug Educ. 24, 253-268.

Link, B.G., Phelan, J.C., 2000. Evaluating the fundamental cause explanation for social disparities in health. In: Bird, C.E., Conrad, P., Freemont, A.M. (Eds.), Handbook of Medical Sociology, 5th ed. Upper Saddle River, New Jersey, pp. 33-46.

Linsky, A.S., Colby Jr., J.P., Straus, M.A., 1986. Drinking norms and alcoholrelated problems in the United States. J. Stud. Alcohol 47, 384-393.

Lynch, J., Kaplan, G.A., Salonen, R., Cohen, R.D., Salonen, J.T., 1995. Socioeconomic status and carotid atherosclerosis. Circulation 92, 17861792

Lynch, J., Smith, G.D., Harper, S., Hillemeier, M., Ross, N., Kaplan, G.A. Wolfson, M., 2004a. Is income inequality a determinant of population health? Part 1: a systematic review. Milbank Q. 82, 5-99.

Lynch, J., Smith, G.D., Harper, S., Hillemeier, M., 2004b. Is income inequality a determinant of population health? Part 2: US national and regional trends in income inequality and age and cause-specific mortality. Milbank Q. 82, 355-400.

Marzuk, P.K., Tardiff, K., Leon, A.C., Hirsch, C.S., Stajic, M., Portera, L., Hartwell, N., 1997. Poverty and fatal accidental drug overdoses of cocaine and opiates in New York City: an ecological study. Am. J. Drug Alcohol Abuse 23, 221-228.

Merlo, J., 2003. Multilevel analytical approaches in social epidemiology: measures of health variation compared with traditional measures of association. J. Epidemiol. Community Health 57, 550-552.

Messner, S.F., Tardiff, K., 1986. Economic inequality and levels of homicide: an analysis of urban neighborhoods. Criminology 24, 297-317.

Midanik, L.T., Greenfield, T.K., 2003. Telephone versus in-person interviews for alcohol use: results of the 2000 National Alcohol Survey. Drug Alcohol Depend. 72, 209-214.

Moore, A.A., Gould, R., Reuben, D.B., Greendale, G.A., Carter, M.K., Zhou, K., Karlamangla, A., 2005. Longitudinal patterns and predictors of alcohol consumption in the United States. Am. J. Public Health 95, 458465 .

Nelson, D.E., Powell-Griner, E., Town, M., Kovar, M.G., 2003. A comparison of national estimates from the National Health Interview Survey and the Behavioral Risk Factor Surveillance System. Am. J. Public Health 93, 1335-1341. 
New York State Division of Alcoholic Beverage Control/State Liquor Authority, 2002. Public Query System. Accessed on November 21, 2002, http://abc.state.ny.us/JSP/query/PublicQueryInstructPage.jsp.

O'Campo, P., 2003. Invited commentary: advancing theory and methods for multilevel models of residential neighborhoods and health. Am. J. Epidemiol. 157 (1), 9-13

Reijneveld, S.A., 1998. The impact of individual and area characteristics on urban socioeconomic differences in health and smoking. Int. J. Epidemiol. $27,33-40$.

Rhodes, J.E., Jason, L.A., 1990. A social stress model of substance abuse. J. Consult. Clin. Psychol. 58, 395-401.

Sandefur, G.D., Pahari, A., 2004. Racial and ethnic inequality in earnings and educational attainment. Soc. Serv. Rev., 199-221.

Schooler, C., Feighery, E., Flora, J.A., 1996. Seventh graders' self-reported exposure to cigarette marketing and its relationship to their smoking behavior. Am. J. Public Health 86, 1216-1221.

Scribner, R.A., Cohen, D.A., Fisher, W., 2000. Evidence of a structural effect for alcohol outlet density: a multi-level analysis. Alcohol Clin. Exp. Res. 24, 188-195.

Stenbacka, M., Allebeck, P., Romelsjo, A., 1993. Initiation into drug abuse: the pathway from being offered drugs to trying cannabis and progression to intravenous drug abuse. Scand. J. Soc. Med. 21, 31-39.

Subramanian, S.V., Kawachi, I., 2004. Income inequality and health: what have we learned so far? Epidemiol. Rev. 26, 78-91.

Substance Abuse and Mental Health Services Administration (SAMHSA), 2003. Overview of findings from the 2002 Survey on Drug Use and Health. Office of Applied Studies, Rockville MD. Accessed February 9, 2006. http://www. oas.samhsa.gov/NHSDA/2k2NSDUH/Overview/2k2Overview.htm.

Suecoff, S.A., Avner, J.R., Chou, K.J., Crain, E.F., 1999. A comparison of New York City playground hazards in high- and low-income areas. Arch. Pediatr. Adolesc. Med. 153, 363-366.

Thomas, V., Wang, Y., Fan, X., 2000. Measuring education inequality: Gini coefficients of education. Accessed on March 13, 2006, http://wdsbeta. worldbank.org/external/default/WDSContentServer/IW3P/IB/2001/02/17/ 00094946_01020605310354/additional/140540323_20041118130703.pdf.

Tseng, M., Yeatts, K., Millikan, R., Newman, B., 2001. Area-level characteristics and smoking in women. Am. J. Public Health 91, 1847-1850.

US Census, 2000. STF-3A Files. US Census Bureau. Available at: http://www. census.gov/main/www/cen2000.html. Accessed July 20, 2006.

Vlahov, D., Galea, S., Ahern, J., Resnick, H., Kilpatrick, D., 2004. Sustained increased consumption of cigarettes, alcohol and marijuana among Manhattan residents after September 11, 2001. Am. J. Public Health 94, 253254.

Wilkinson, R.G., 1992. Income distribution and life expectancy. Br. Med. J. 304, $165-168$.

Wilson, J.Q., 1996. Foreword. In: Kelling, G.L., Coles, C.M., Fixing (Eds.), Broken Windows: Restoring Order and Reducing Crime in Our Communities. Simon and Schuster, New York.

Zeger, S.L., Liang, K.-Y., 1986. Longitudinal data analysis for discrete and continuous outcomes. Biometrics 42, 121-130. 